\title{
Study of the clinical spectrum of AUB (FIGO AUB Systems) and women's attitude towards its management at Anugrah Narayan Magadh Medical College and Hospital, Gaya, Bihar, India
}

\author{
Ruby Kumari*, Lata Shukla Dwivedy, Sweta Gupta, Surabhi, \\ Madhuri Choudhary, Arti Kumari
}

Department of Obstetrics and Gynecology, Anugrah Narayan Magadh Medical College and Hospital, Gaya, Bihar, India

Received: 17 September 2020

Revised: 11 November 2020

Accepted: 12 November 2020

*Correspondence:

Dr. Ruby Kumari,

E-mail: dr.rubybharti@gmail.com

Copyright: (c) the author(s), publisher and licensee Medip Academy. This is an open-access article distributed under the terms of the Creative Commons Attribution Non-Commercial License, which permits unrestricted non-commercial use, distribution, and reproduction in any medium, provided the original work is properly cited.

\section{ABSTRACT}

Background: AUB has significant impact on quality of life of women related to health specially in developing countries including India. FIGO AUB systems are universally accepted. Aim was to study the clinical spectrum of AUB according to the FIGO AUB systems and women's attitude towards its management.

Methods: Cross sectional prospective study was carried out in the department of Obstetrics and Gynaecology, ANMMCH, Gaya, a tertiary care center, among women of 15-55 years age groups having complain related to abnormal uterine bleeding, for 1 year from $1^{\text {st }}$ May 2019 to $30^{\text {th }}$ April 2020 on 1000 patients. Data was collected and analyzed by percentage and proportions.

Results: Prevalence of AUB was maximum among 15-30 years age group of patients (46.80\%). Most of the patients belong to lower $(62.5 \%)$ class, rural area $(68 \%)$ and were anaemic $(62.5 \%)$. Ovulatory dysfunction $(55 \%)$ was most common cause for AUB, maximum patients choose surgical management (hysterectomy) but after counselling, most of them shifted to medical management.

Conclusions: This study suggests more conservative approach for management of AUB and emphasizes the importance of awareness for clinical spectrum of AUB among women so that they can be self-motivated for early treatment and unnecessary hysterectomy can be avoided.

Keywords: AUB, FIGO AUB systems, Ovulatory dysfunction, Surgical management

\section{INTRODUCTION}

Abnormal uterine bleeding (AUB) is defined as bleeding from the uterine corpus that is abnormal in regularity, volume, frequency or duration and occurs in the absence of pregnancy and when has been present for majority of the last 6 months then it is chronic AUB. Acute AUB is defined as an episode of bleeding that, in clinician opinion, is of sufficient quantity requiring immediate intervention to minimize/prevent further blood loss. ${ }^{1,2}$ It is usually associated with discomfort, anxiety, iron deficiency anemia, decreased work productivity and income, negative impact on relationship with partner and many result in surgical interventions including hysterectomy. ${ }^{3}$ AUB is reported to occur as $9-14 \%$ women between menarche and menopause. ${ }^{4}$ The prevalence increases with age, reaching $24 \%$ in women aged 36-405 and varies in each country. In India the reported prevalence of AUB is around 17.9\%. ${ }^{6}$

FIGO AUB systems are universally accepted for normal and abnormal uterine bleeding symptoms and 
classification of causes known by the acronym PALMCOEIN (polyp, adenomyosis, leiomyoma, malignancy and hyperplasia; coagulopathy, ovulatory dysfunction, endometrial, iatrogenic and not otherwise classified) of AUB in the reproductive years. ${ }^{7}$ The FIGO AUB systems classifies uterine bleeding abnormalities by bleeding pattern as well as by etiology. There is a plethora of potential causes which may coexist in an individual and a single responsible etiology of AUB may have a spectrum of bleeding pattern. As Indian women are careless about their health-related issues, they delay visit to health provider and have poor compliance of follow-up. The aim and objective of this study was to find out the clinical spectrum of AUB and women's attitude towards its management.

\section{METHODS}

It was a cross-sectional prospective study, conducted from 1st May 2019 to 30th of April 2020 in the department of Obstetrics and Gynaecology in Anugrah Narayan Magadh Medical College and Hospital (ANMMCH), Gaya, Bihar, India after permission from ethical committee of the institute.

\section{Inclusion criteria}

All women aged 15-55 years, having menstrual abnormality presented in Gynaecology OPD and agreed for study and subsequent follow-up.

\section{Exclusion criteria}

Bleeding per vaginum due to disturbed pregnancy/ vaginal or cervical cause. Patients on hormonal contraception/hormone replacement therapy. Postmenopausal bleeding. Poor candidate of follow-up.

A detailed history was collected from patients regarding age, parity, educational and socioeconomic status, residential area, menstrual history (including age of menarche, LMP, regularity, frequency, duration of flow, volume of flow, associated with pain or not), relevant medical/ surgical/ drug history obtained. Family history of coagulopathy searches out. General examination (general condition of patient height, weight, BMI, pallor, icterus, etc) and Gynae. examination (breast examination, P/A, P/S, P/V examination) done. After pregnancy ruled out by urine pregnancy test, relevant blood test (CBC-Hb, platelets, S/TSH, S/prolactin, LFT, PT, PTT), USG for evaluation of uterus and adnexa and endometrial thickness advised, indicated hysteroscopy followed by endometrial biopsy done. Symptomatic treatment given to patients on first visit. Patients were instructed to maintain menstrual diary for 3 months. Etiological diagnosis of AUB was made based upon clinical spectrum of menstrual pattern, general and Gynae. examination and different tests results. After final diagnosis of AUB, patients were asked to choose treatment options - either medical or surgical method, their responses and all other findings were recorded in a proforma prepared for this study. Statistical tool used was MS office Excel and SPSS version 17.

\section{RESULTS}

Table 1 showing demographic details of the patients; maximum patients (No. 468; 46.8\%) came under age group of 15-30 years and having parity P2 or more, (No. $280 ; 28 \%)$. Table 2 shows HMB was major complain (41\%), most of the patients having more than one complain. Table 3 shows prevalence of etiologies of AUB. Most common cause of AUB was ovulatory dysfunction, $\mathrm{No}=550$, (55\%). However, in many cases there were co-existing of many causes in a single patient.

Table 1: Demographic detail $(n=1000)$.

\begin{tabular}{|lll|}
\hline Age in years & No. & Percentage \\
\hline $15-30$ & 468 & 46.8 \\
\hline $31-35$ & 125 & 12.5 \\
\hline $36-40$ & 219 & 21.9 \\
\hline $41-45$ & 94 & 9.4 \\
\hline $46-55$ & 94 & 9.4 \\
\hline Parity & & \\
\hline P0 & 190 & 19.0 \\
\hline P1 & 60 & 6.0 \\
\hline P2 & 280 & 28.0 \\
\hline P3 & 250 & 25.0 \\
\hline$>$ P4 & 220 & 22.0 \\
\hline Education & & \\
\hline Nill & 230 & 23.0 \\
\hline Primary & 270 & 27.0 \\
\hline Secondary & 132 & 13.2 \\
\hline High & 98 & 9.8 \\
\hline Intermediate & 140 & 10.4 \\
\hline Graduate & 130 & 10.3 \\
\hline Socioeconomic status & & \\
\hline Lower class & 250 & 25.0 \\
\hline Upper lower class & 375 & 37.5 \\
\hline Middle class & 225 & 22.5 \\
\hline Upper middle class & 150 & 15.0 \\
\hline Upper class & 0 & $0.0 \%$ \\
\hline Residence & & \\
\hline Rural & 680 & 32.0 \\
\hline Urban & 320 & \\
\hline & & \\
\hline & & \\
\hline & & \\
\hline & & \\
\hline
\end{tabular}

Table 4 shows patient's initial choice of treatment was surgical (hysterectomy), irrespective to aetiology and age. After counselling of hazards of hysterectomy and postmenopausal effects on health if done at inappropriate age and availability of conservative managements. After counselling about $50 \%$ patients shifted from surgical to medical treatment. $10 \%$ patient were confused, indecisive regarding treatment options, they said "what is right do that". 
Figure 1-3 showing distribution of major causes of AUB in different age group. AUB-O, AUB-L and AUB-A were more prevalent in 15-30years (60\%), 45-55years $(50 \%)$, $31-45$ years $(60 \%)$ age group patients respectively).

Table 2: Presenting complain of patients and prevalence of anemia (n-1000).

\begin{tabular}{|lll|}
\hline Presenting menstrual complain & No. & Percentage \\
\hline Heavy menstrual bleeding & 410 & 41.0 \\
\hline Light menstrual bleeding & 250 & 25.0 \\
\hline Prolonged duration of flow (>8d) & 400 & 40.0 \\
\hline Irregular cycle (>9 days variation & 350 & 35.0 \\
\hline No bleeding & 125 & 12.5 \\
\hline Frequent cycle (<24 days) & 63 & 6.3 \\
\hline Infrequent cycle (>38 days) & 350 & 35.0 \\
\hline Anemic patient & 625 & 62.5 \\
\hline
\end{tabular}

Table 3: Etiologies responsible for AUB (n-1000).

\begin{tabular}{|lll|}
\hline Etiologies & No. & Percentage \\
\hline Polyp & 65 & 6.5 \\
\hline Adenoma & 150 & 15.0 \\
\hline Leiomyoma & 200 & 20.0 \\
\hline Malignancy and hyperplasia & 20 & 2.0 \\
\hline Coagulopathy & 10 & 1.0 \\
\hline Ovulatory dysfunction & 550 & 55.0 \\
\hline Endometrial & 5 & 0.5 \\
\hline Iatrogenic & 0 & 0.0 \\
\hline Not otherwise classified & 0 & 0.0 \\
\hline
\end{tabular}

Table 4: Patient's choice after the counselling for treatment options (n-1000).

\begin{tabular}{|lllll|}
\hline $\begin{array}{l}\text { Treatment } \\
\text { options }\end{array}$ & \multicolumn{2}{l}{$\begin{array}{l}\text { Before } \\
\text { counselling }\end{array}$} & \multicolumn{2}{l|}{$\begin{array}{l}\text { After the } \\
\text { counselling }\end{array}$} \\
\hline Medical & No. & \% & No. & \% \\
\hline Surgical & 320 & 32 & 600 & 60 \\
\hline Indecisive & 580 & 58 & 300 & 30 \\
\hline
\end{tabular}

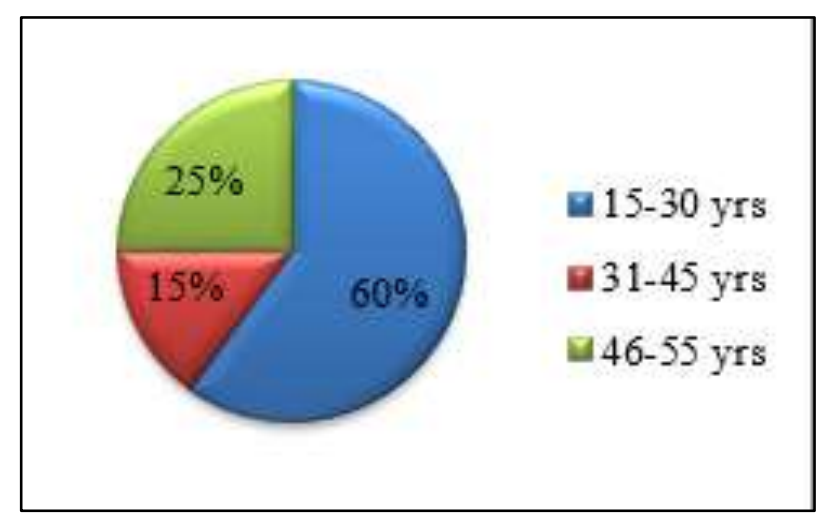

Figure 1: Distribution of etiologies of AUB in AUB - O age group.

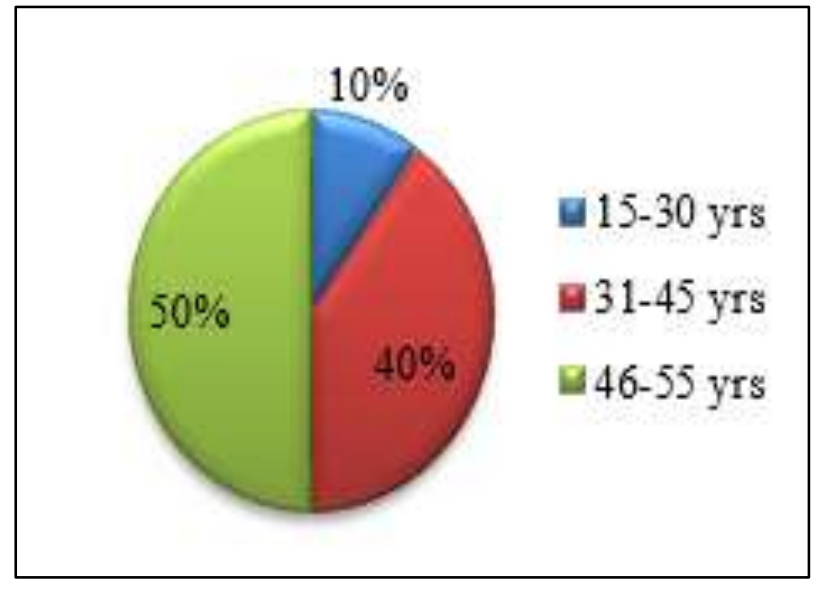

Figure 2: Distribution of etiologies of AUB in AUB - L age group.

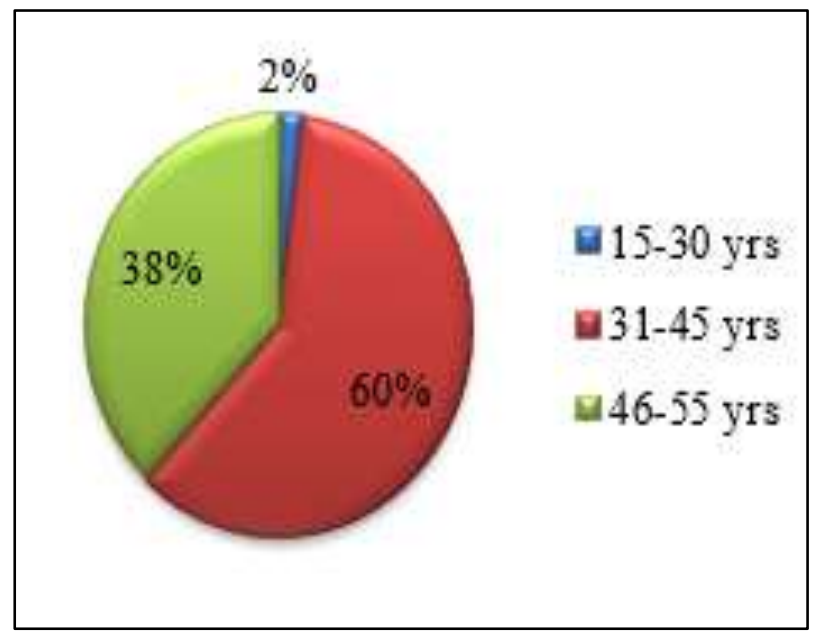

Figure 3: Distribution of etiologies of AUB in AUB - A age group.

\section{DISCUSSION}

AUB is leading cause to visit a gynaecologist. Its prevalence and management both badly affect women's life. In 2011 FIGO has developed universally accepted a standard etiopathogenesis classification known by acronym PALM-COEIN". ${ }^{1}$ The components of PALM group are discrete (structural) that can be measured with imaging techniques and/or histopathology where COEIN group is related to entities that is not defined by imagine or histopathology (non-structural), the "not otherwise classified" category includes a spectrum of potential entities that may or may not be defined by imagine techniques or histopathologies. ${ }^{7}$

The AUB term is paired with descriptive terms to denote bleeding patterns associated with AUB, such as heavy menstrual bleeding and intermenstrual bleeding and its etiology or etiologies (Figure 4). 


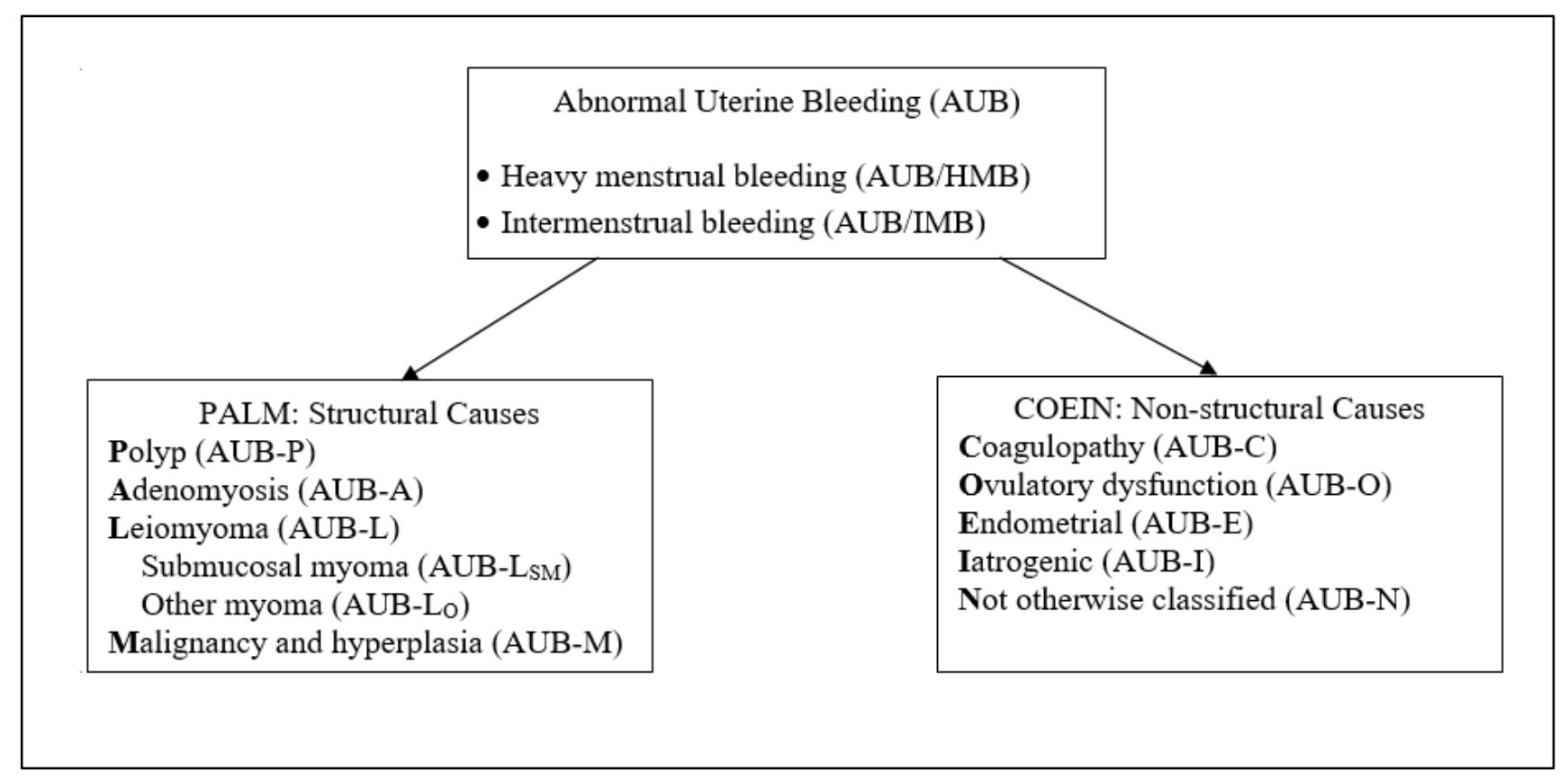

Figure 4: FIGO AUB system 2.

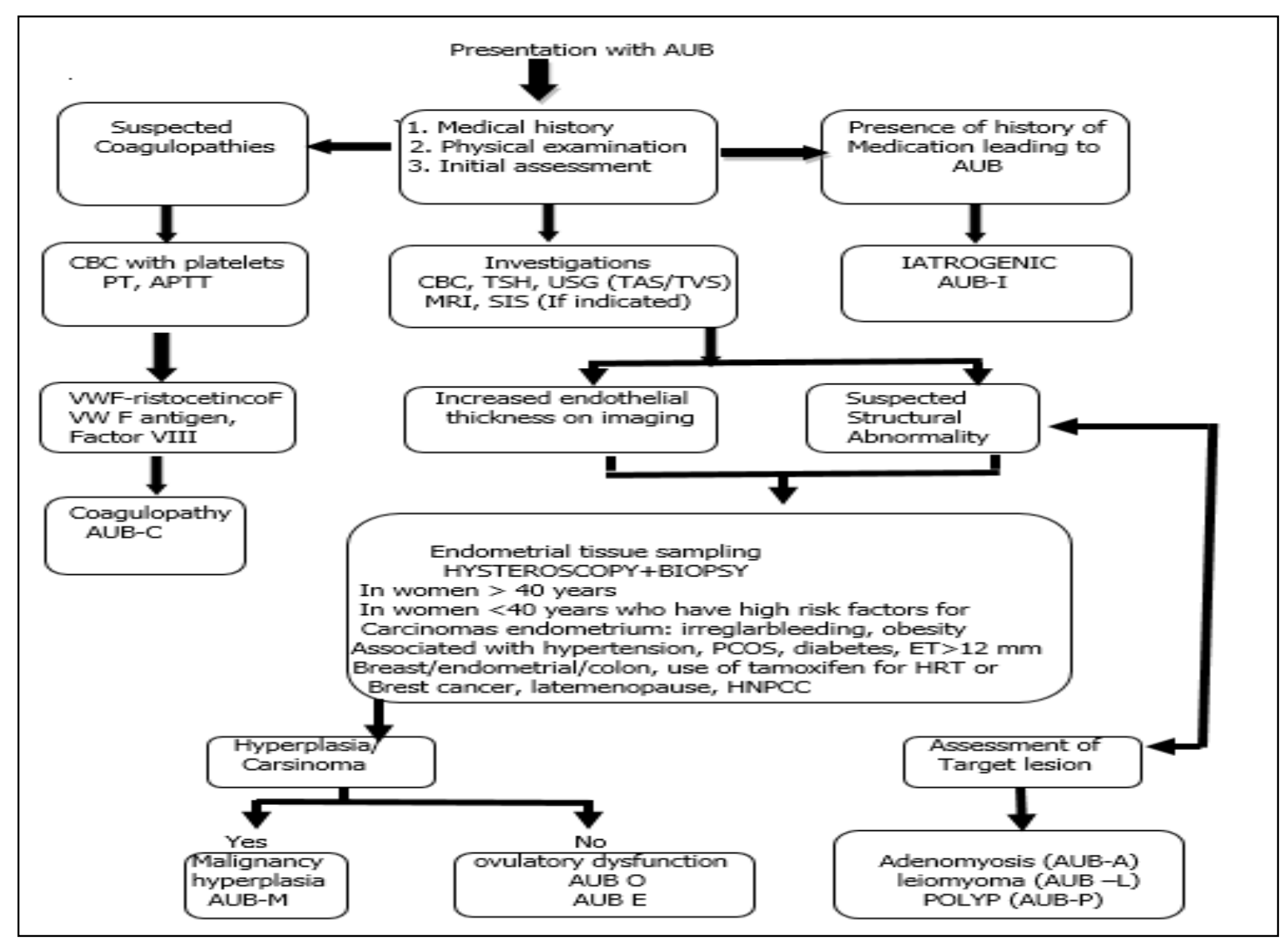

Figure 5: Algorithm for the diagnosis of AUB.

Presence of one or a combination of coagulopathy, disorder of ovulation or primary endometrial disorder replace the term "DUB". ${ }^{1,2}$ FOGSI have developed Good Clinical Practice guidelines for diagnosis and 
management of AUB with the help of FIGO AUB Systems and other guidelines with keeping Indian scenario in mind. ${ }^{8-10}$ For diagnosis of AUB, recommendations are given aetiology wise according to PALM-COEIN systems (Figure 5).

Abandon the old terminologies and use PALM-COEIN classification. ${ }^{11}$ Obtained a through history and to conduct a physical examination to direct the need for further investigations and treatment. Drug/H for concomitant use of any medications, which may cause of AUB. Criteria for positive screen for coagulopathies. (Grade B, Level 4). History of heavy bleeding starting from menarche. One of the following conditions-PPH, surgery-related bleeding, bleeding with dental work. Atleast two or more of following conditions: one episode of bruising per month, one episode of Epistaxis per month, frequent gum bleeding, family history of bleeding symptoms.

Examination includes assessment of weight, BMI, pallor, thyroid, breast, acne, FG Score (if hirsuitism is present), abdominal, $\mathrm{P} / \mathrm{S}$ and $\mathrm{P} / \mathrm{V}$ examination.

Recommendations on lab testing are $\mathrm{CBC}$ to be done in all patients to rule out pregnancy. Bleeding time, platelet count, prothrombine time, partial thromboplastine time to be done in all cases with a positive screen for Coagulopathies. Further testing for vWD, ristocetin cofactor activity, factor VIII activity and von Willebrand factor antigen is recommended in consultation with a haematologist, TSH to be done.

Recommendations on imagine are ultrasonography to evaluate uterus, adnexa and endometrial thickness (grade A; level 1). Doppler ultrasonography is in suspected arteriovenous malformation, malignancy cases and to differentiate between fibroid and adenomyomas. 3D USG is for evaluating intracavitory and intramyometrial lesion in selected patients and for fibroid mapping and typing. SIS is if intracavitary lesion is suspected and hysteroscopy is not available (grade A; level 1). Hysteroscopy is for diagnosis of intracavitory lesion and type of myoma (grade A; level 1).

MRI is to differentiate between fibroids and adenomyomas and for mapping exact location of fibroids while planning conservative surgery and prior to therapeutic embolisation for fibroids (grade A; level 3).

Endometrial histopathology recommendations are endometrial histopathology to be done in women $>40$ years (grade A; level 2), <40 years with high-risk factors for carcinoma endometrium, AUB unresponsive to medical treatment (grade A; level 2). Endometrial aspiration is the preferred procedure for obtaining endometrial sample for histopathology. If endometrium is thick on imaging, but HPE is inadequate or atrophic, hysteroscopy should be performed to rule out polyps (grade A; level 2).
Dilatation and curettage should not be the procedure of choice for endometrial assessment.

\section{Recommendations for management of AUB (etiology wise) are}

\section{AUB-P:}

Hysteroscopic polypectomy- in younger women with desirous of fertility (grade A; level 1). Multiple endometrial polyps and not desirous of fertilityhysteroscopic polypectomy followed by LNG-IUS insertion after confirmation of benign lesion on histopathology (grade A; level 2), if it is malignancy on histology, further management should be as AUB-M.

\section{$A U B-A$ :}

Management should consider the age, symptoms and association with other conditions (leiomyomas, polyps and endometriosis). AUB-A, with desirous of fertility, progestogens especially LNG-IUS is recommended as first-line therapy but resistant to LNG-IUS/unwilling to use LNG-IUS, Gonadotropin Releasing Hormone $(\mathrm{GnRH})$ agonists with add-back therapy is recommended as second-line therapy (Grade A; Level 1).

\section{$A U B-A$ :}

Not desirous of fertility, medical management using longterm GnRH agonists and add-back therapy can be initiated. COCs, danazol, NSAIDs and progestogens can be offered for symptomatic relief where LNG-IUS and $\mathrm{GnRH}$ agonists cannot be indicated. In case of failure/refusal for medical management, vaginal or laparoscopic hysterectomy is indicated (Grade A; Level 1).

\section{$A U B-L:$}

Treatment should depend upon age, parity, symptoms, fertility desires. Various options are-Symptomatic intramural or subserosal myomas (grade 2-6) and desirous of fertility/uterus can be managed with tranexamic acid or COCs or NSAIDs (1st line) or LNGIUS (2nd line choice) if other medical treatment fails and patient is not trying to conceive for at least 1 year (grade A; level 1). If medical treatment fails or if myoma is causing infertility, myomectomy is recommended (grade A; level 3). Above 40 years of age, with completed family, hysterectomy is the definitive treatment; however, medical management including LNG-IUS may be tried in small fibroids $(<4 \mathrm{~cm}$ diameter) before undergoing definitive surgery (grade B; level 3).For short-term management (up to 6 months), GnRH agonists with addback therapy is an option in perimenopausal women, prior to myomectomy or for improving general condition (grade A; level 1). For long-term management of symptomatic leiomyomas, use LNG-IUS (except in AUB-L 0 and 1 grade) as first-line management. Newer 
promising options are progesterone receptor modulators such as Ulipristal acetate and low-dose mifepristone (510mg) (grade A; level 1).

\section{AUB-M:}

Specific recommendations are- AUB-M with endometrial malignancy, follow standard protocol for management of malignancy (grade B; level 4). AUB-M with endometrial hyperplasia (a) with atypia, do hysterectomy (grade B; level 2) (b) without atypia, LNG-IUS is as first-line therapy; oral progestins can be used if LNG-IUS is contraindicated (grade A; level 1). ${ }^{12}$

\section{$A U B-C$ :}

Non-hormonal treatment with tranexamic acid (1 gm qid) as primary option and hormonal treatment with COCs/LNG-IUS as secondary option* are recommended in consultation with a haematologist with the following considerations (grade A; level 2).

For refractory case of vWD with uncontrolled AUB with above medical management, specific factor replacement where possible or desmopressin in refractory cases to be given. When surgical interventions are indicated, appropriate pre-, intra- and postoperative management of bleeding should be done.

*NSAIDs are contraindicated as they can alter platelet function and interact with drugs that might affect liver function and production of clotting factors. *Injectables (GnRH agonists) are contraindicated except in mild coagulation abnormalities. When administered, prolonged pressure should be applied at injection site (Singh et al 2013).

\section{$A U B-O$ :}

If not desiring conception presently, COCs as first-line therapy for 6-12 months (grade A; level 1). Cyclic luteal phase progestins (10-14 days) should be used as specific treatment in AUB-O cases (Grade A; Level 1). Norethisterone cyclically (for 21 days) is given as initial therapy in acute episodes of bleeding for short-term management of 3 months (Grade B; Level 4). Surgical intervention is only recommended in persistent AUB or failure of medical management. (Grade A; Level 4). If COCs are contraindicated or unwilling, LNG-IUS is recommended if she wishes to use it for at least 1 year (Grade A; Level 1). In adolescents' patients, both hormonal and non-hormonal therapies can be prescribed, (Grade A; Level 4).

\section{AUB-E (Endometrial):}

Recommendations are similar to the management of AUB (O). (Grade A; Level 4). ${ }^{13}$

\section{AUB-I (Iatrogenic causes):}

Medications causing AUB should be changed to other alternatives, if no alternatives are available, LNG-IUS is recommended (Grade A; Level 1).

$A U B-N$ :

Idiopathic AUB cases and desire effective contraception, LNG-IUS is as first-line therapy. (Grade A; Level 1). Desirous of continued fertility, in whom, LNG-IUS are contraindicated, use of COCs are as second line therapy (Grade A; Level 1).

$A U B-N$ :

That are mainly cyclic or predictable in timing, nonhormonal options such as NSAIDs and tranexamic acid are recommended (Grade A; Level 1). When medical or conservative surgical treatments (such as ablation) have failed or contraindicated, GnRH agonists along with addback hormone therapy are recommended to reduce idiopathic AUB.

Uterine artery embolisation is recommended for A-V malformations. Hysterectomy is suggested as last resort (Grade B; Level 4). Ovulatory dysfunctions (55\%) were most common cause followed by leiomyoma $(20 \%)$ and Adenomyosis (15\%), similar to study done by Gauri et al, where maximum number of patients were categorised under ovulatory dysfunctions $(27 \%)$ followed by leiomyoma $(24.67 \%)$, however in some study combined causes mostly leiomyoma and Adenomyosis were found most common cause for AUB. ${ }^{14-16}$

In present study, in some patients there were mixed etiologies of AUB. AUB-O, AUB-L and AUB-A were more prevalent in 15-30years (60\%), 45-55years $(50 \%)$, $31-45$ years $(60 \%)$ age group patients respectively showing that the prevalence of Leiomyoma and Adenomyosis increases with age similar to study done by Sun et al, where AUB-O was mainly prevalent between ages 20 and 34, the peak prevalence of AUB-A was between $40-44$ years $(34.6 \%)$ and that of AUB-L was between 45-49 years (on higher side of age). ${ }^{17}$

In this study patients were asked to choose option between medical and surgical treatment (hysterectomy). $68 \%$ patients choose hysterectomy irrespective to age and cause but after counselling of hazards of hysterectomy and postmenopausal effects on health if done at inappropriate age (if conservative managements are available). After counselling, about $50 \%$ patients shifted (from surgical) to medical treatment. 10\% patients were confused, indecisive regarding treatment options, they said "what is right do that".

This study shows there is need of awareness among women for clinical spectrum of AUB so that they can understand treatment protocol and also recommends towards more conservative approach so that unnecessary load of hysterectomy can be overcome, similar finding by 
Abid et al where they emphasise need to adopt a more conservative approach to treatment. ${ }^{18}$

In this study, medical options given to the patients were Hormonal: COC, Cyclic Luteal phase progestins, Cyclic Norethisterone, LNS - IUS and GnRH analogues. b) Non-hormonal: Antifibrinolytics, NSAIDS depending upon clinical conditions, severity of the conditions, suspected etiologies, desire for future fertility and contraindications of the use of hormonal drugs and hysterectomy as a surgical option.

Usually delayed visit of patients in Gynae OPD, by till date they became much annoyed by the problems and looking for permanent solution in the form of Hysterectomy, as their thinking were that they have completed their family, functions of the uterus has been over, so get removal of uterus. It is cumbersome to take medicine daily. Financially not able to buy costly medicine like LNG-IUS, GnRH analogues. Most patients belonging to rural area (68\%), as a whole the transportation cost was high, not able to bear it, so it was also a factor for poor follow-up of the patients. Usually counselled by local practitioners/ dais/ quacks for hysterectomy as AUB is a symptom of cancer.

Patients were counselled for different causes of AUB and their different management, availability of COC (in govt. hospital free of cost) or other cheaper medicines, making availability of LNG - IUS at much lower price. Also counselled them for hazards of Hysterectomy and postHysterectomy effects on body if done at inappropriate age (if conservative options are available). The effects of counselling were that about $50 \%$ patient shifted from surgical options to medical options. In this study we found that maximum patient were illiterate, poor, belong to remote area, have myth related to AUB, wanted cheaper and fast management of AUB.

\section{Limitations}

It has small sample size. There is still a need to further increase the sample size in the future studies to support the findings.

\section{CONCLUSION}

This study suggests individualized and more conservative approach for management of AUB and also emphasizes need of awareness program for clinical presentations of AUB, its different treatment options and effects of unnecessary hysterectomy on women's morbidity and mortality. Cost effective investigations, costly medicines like LNS -IUS, GnRH should be available in govt. hospital (free of cost). Thus, decreasing the burden of cost of management and improve overall conditions of the women.

Funding: No funding sources Conflict of interest: None declared
Ethical approval: The study was approved by the Institutional Ethics Committee

\section{REFERENCES}

1. Munro MG, Critchley HO, Broder MS. FIGO classification system (PALM-COEIN) for causes of abnormal uterine bleeding in non-gravid women of reproductive age. Int J Gynaecol Obstet. 2011;113(1):313.

2. Committee on practice bulletins-gynecology. Practice bulletin no. 128: diagnosis of abnormal uterine bleeding in reproductive-aged women. Obstet Gynecol. 2012;120(1):197-206.

3. Millar WJ. Hysterectomy, 1981/82 to $1996 / 97$. Health Report. 2001;72:9-22.

4. Fraser IS, Langham S, Hochgraeber UK. Health related quality of life and economic burden of abnormal uterine bleeding. Expert Rev Obstet Gynaecol. 2009;4:179-89.

5. Harlow SD, Campbell OMR: Epidemiology of menstrual disorders in developing countries: a systematic review. Int J Obstet Gynaecol. 2004;111:616.

6. Sharma A, Dogra Y. Trends of AUB in tertiary centre of Shimla Hills. J Midlife Health. 2013;4:67-8.

7. Munro MG, Critchley HO, Broder MS. The two FIGO systems for normal and abnormal uterine bleeding symptoms and classification of causes of abnormal uterine bleeding in the reproductive years: 2018. Int Gynaecol Obstet. 2018;143:393-408.

8. Good Clinical Practice guidelines on AUB.FOGSI. Available at http://www.fogsi.org/good-clinical-practice guidelines on-aub/. Accessed on 2 May 2016.

9. ACOG Committee on Practice Bulletins Gynecology. Polycystic ovary syndrome. Obstet Gynecol. 2009;114(4):936-949.

10. Committee on practice bulletins-gynecology. Diagnosis of abnormal uterine bleeding in reproductive-aged women. Obstet Gynecol. 2012;120(1):197-206.

11. Fraser IS, Critchley HO, Munro MG. A process designed to lead to international agreement on terminologies and definitions used to describe abnormalities of menstrual bleeding. Fertil Steril. 2007;87(3):466-76.

12. Quinn MA, Benedet JL, Odicino F, Maisonneuve P, Beller U, Creasman WT. Carcinoma of the cervix uteri. FIGO 26th annual report on the results of treatment in gynaecological cancer. Int $\mathbf{J}$ Gynecol Obstet. 2006;95(1):43-103.

13. Revised American society for reproductive medicine classification of endometriosis: 1996. Fertil Steril 1997;67(5):817-21.

14. Amulya C, Kumari PD, Yernagula J. Systematic grouping and critical analysis of abnormal uterine bleeding (AUB) cases according to FIGO'S PALMCOEIN'S classification a retrospective study. J Evid Based Med Healthc. 2017;4(45):2730-6.

15. Gouri SRS, Lakshmi PV, Rani NG, Kumar NA. Categorization of the causes of abnormal uterine bleeding according to PALM-COEIN classification. Int J Sci Stud. 2016;4(2):104-7.

16. Qureshi FU, Yususf AW. Distribution of causes of abnormal uterine bleeding using the new FIGO 
classification system. J Pak Med Assoc. 2013;63(8):971-5.

17. Sun Y, Wang Y, Mao L, Wen J, Bai W. Prevalence of abnormal uterine bleeding according to new International Federation of Gynaecology and Obstetrics classification in Chinese women of reproductive age. Medicine. 2018;97:31.

18. Abid M, Hashmi AA, Malik B, Haroon S, Faridi N, Edhi MM. Clinical pattern and spectrum of endometrial pathologies in patients with abnormal uterine bleeding in Pakistan: need to adopt a more conservative approach to treatment. BMC Women's Health. 2014;14:132.

Cite this article as: Kumari R, Dwivedy LS, Gupta S, Surabhi, Choudhary M, Kumari A. Study of the clinical spectrum of AUB (FIGO AUB Systems) and women's attitude towards its management at ANMMCH, Gaya, Bihar, India. Int J Reprod Contracept Obstet Gynecol 2021;10:178-85. 